\title{
Early history of LGBT tobacco control: CLASH at 25
}

\author{
Naphtali Offen, ${ }^{1}$ Elizabeth A Smith, ${ }^{1}$ Bob Gordon ${ }^{2}$
}

In the spring of 2016, the Food and Drug Administration (FDA) launched a national campaign, This Free Life, to discourage lesbian, gay, bisexual and transgender (LGBT) people from smoking (see front cover). This Free Life would have been only a fantasy 25 years ago, when a few LGBT advocates met during the campaign that made San Francisco restaurants smoke-free. They suspected that LGBT smoking rates were high and founded the first organisation dedicated to LGBT tobacco control, the Coalition of Lavender-Americans on Smoking or Health (CLASH). Its mission was three-pronged: to work within the LGBT community to raise awareness of tobacco's deadliness, to lobby mainstream tobacco control for the resources to do so and to contribute to the larger tobacco control movement.

\section{WORKING WITHIN THE LGBT COMMUNITY}

At the time, HIV/AIDS, with few effective treatments available, commanded the community's attention. Other priorities included sodomy law repeal; legalising LGBT military service; and fighting antigay discrimination and violence. Marriage equality was not even a dream. The community was also grappling with high alcohol and drug use. With this burden, tobacco control was far from a priority. In this context, industry framing of smoking as a personal freedom had great salience for the LGBT community.

Hampered by a lack of data, CLASH instigated one of the first studies confirming that sexual minorities smoked much more than others. ${ }^{1}$ We now know that tobacco is a 'gay issue' for many reasons: in addition to disproportionately high LGBT prevalence rates, ${ }^{2}$ the tobacco industry targets the community, ${ }^{3}$ and tobacco use compromises AIDS prognoses $^{4}$ and hormone therapy. ${ }^{5}$ Possible explanations for higher LGBT smoking rates include response to the stresses of

\footnotetext{
${ }^{1}$ Department of Social and Behavioral Sciences, University of California, San Francisco, San Francisco, California, USA; ${ }^{2}$ California LGBT Tobacco Education Partnership, San Francisco, California, USA

Correspondence to Naphtali Offen, Department of Social and Behavioral Sciences, University of California, San Francisco, P.O. Box 0612, San Francisco,

CA 94143, USA; naphtali.offen@ucsf.edu
}

marginalisation; a smoky bar culture historically central to coming out; an 'outlaw' identity and the belief that smoking is inextricably linked to being gay. ${ }^{6}$

Despite accumulating evidence of tobacco's harms, getting the community to take up the issue remained a struggle. By the early 1990s, the LGBT movement had made enough progress in changing how society viewed its LGBT citizens such that Philip Morris advertised in a gay publication for the first time. ${ }^{7}$ Some LGBT spokespeople celebrated the recognition, but CLASH argued that being enticed to use a deadly product did not further gay liberation. When Philip Morris settled an AIDS Coalition to Unleash Power (ACT-UP) boycott by committing millions to AIDS organisations, CLASH argued that donations from the industry silenced community opposition to smoking. ${ }^{8}$ Sometimes, it was necessary to challenge community organisations that were working with the tobacco industry, being sensitive not to interfere with their mission. ${ }^{9}$ In the early 2000s, CLASH staged a demonstration that convinced the Gay and Lesbian Alliance Against Defamation to stop hosting Brown \& Williamson-sponsored smoking lounges at its banquets. ${ }^{10}$

In addition to focusing on the industry as the source of the epidemic, CLASH reached out to LGBT smokers. The Last Drag, initiated in 1991 and still facilitated by CLASH member Gloria Soliz, is the first cessation programme established for LGBT and HIV-positive smokers. It has served as a model for other cessation curricula and enjoys a high quit rate, testimony to the effectiveness of providing cessation services within a supportive community. ${ }^{11}$

\section{REACHING OUT TO MAINSTREAM TOBACCO CONTROL}

As LGBT favourability increased, CLASH achieved more success in gaining recognition from mainstream tobacco control. California established priority populations to provide special services to ethnic communities suffering disproportionately from tobacco. Early attempts to include the LGBT community as a priority population were met with resistance from multiple directions. Other communities were reluctant to share their scarce resources; public health had yet to conceive of non-ethnic priority populations; and a conservative Governor did not want to acknowledge the LGBT community. Eventually, mainstream tobacco control recognised the advantages of partnering with non-ethnic groups such as the LGBT community and those of low socioeconomic status. CLASH could organise the LGBT community around tobacco control measures, and educate the ethnic networks about their LGBT members.

\section{DOING OUR PART FOR TOBACCO CONTROL}

CLASH has long been active in broader tobacco control issues. In the early 2000s, CLASH persuaded KQED public television to cancel advertisements promoting Philip Morris's quit smoking website, which had been evaluated as ineffective and a public relations ploy. ${ }^{12}$ In the late 2000s, CLASH member Bob Gordon, as director of the California LGBT Tobacco Education Partnership, was key to banning cigarette sales in San Francisco pharmacies. ${ }^{13}$ CLASH persuaded more than 100 LGBT elected officials ${ }^{14}$ and community organisations $^{15}$ to go public with a pledge not to accept financial support from the tobacco industry in order to further de-normalise it and inoculate leadership against its influence. This campaign was repurposed by the American Cancer Society, targeting all California state legislators. These tobacco control victories, not gay-specific, benefit everyone, and help cement ties with mainstream tobacco control.

\section{PROGRESS}

The landscape has changed dramatically in 25 years. In 2002, CLASH hosted more than 100 advocates and researchers at an LGBT tobacco control summit. In 2006, the Centers for Disease Control and Prevention (CDC) established a national LGBT tobacco control network. International tobacco control conferences have included LGBT presentations and networking events. LGBT-specific tobacco control advertising campaigns, conferences, smoke-free pride events, community projects, cessation services and research protocols have proliferated. After initial hesitance, partially a result of homophobia, mainstream tobacco control has embraced us as a respected partner.

\section{LOOKING TO THE FUTURE}

We have been less successful in persuading the LGBT community that tobacco is more than a personal choice. LGBT films 
still glamorise tobacco; gay bars and pride events are lax in enforcing smoke-free laws; and LGBT youth are still exposed to industry bar promotions. ${ }^{16}$ Although in many countries, LGBT people experience far less stigma than in years past, smoking prevalence in the community remains high, ${ }^{17}$ suggesting that LGBT-specific tobacco control could still be useful. Sadly, greater challenges, beyond tobacco disease, remain for those in places where same-sex relationships are still criminalised or pathologised and the community must stay hidden. LGBTs have made great strides towards acceptance and great contributions to tobacco control. We need allies who realise that reducing stigma may be a tobacco control measure in itself, or at least a first step to improving the health of our community.

Contributors NO wrote the first draft. All authors helped revise and edit.

Competing interests None declared.

Provenance and peer review Commissioned; internally peer reviewed.

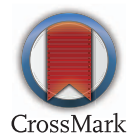

To cite Offen N, Smith EA, Gordon B. Tob Control 2016:25:502-503.

\section{SLinked}

- http://dx.doi.org/10.1136/tobaccocontrol-2015052660

Tob Control 2016;25:502-503.

doi:10.1136/tobaccocontrol-2016-053273

\section{REFERENCES}

1 Stall RD, Greenwood GL, Acree M, et al. Cigarette smoking among gay and bisexual men. Am J Public Health 1999:89:1875-8.

2 Ryan $\mathrm{H}$, Wortley PM, Easton A, et al. Smoking among lesbians, gays and bisexuals: a review of the literature. Am J Prev Med 2001;21:142-9.

3 Goebel K. Lesbians and gays face tobacco targeting. Tob Control 1994:3:65-7.

4 Helleberg M, Afzal S, Kronborg G, et al. Mortality attributable to smoking among HIV-1-infected individuals: a nationwide, population-based cohort study. Clin Infect Dis 2013;56:727-34.

5 Wierckx K, Elaut E, Declercq E, et al. Prevalence of cardiovascular disease and cancer during cross-sex hormone therapy in a large cohort of trans persons: a case-control study. Eur J Endocrinol 2013:169:471-8

6 Remafedi G. Lesbian, gay, bisexual, and transgender youths: who smokes, and why? Nicotine Tob Res 2007;9(Suppl 1):S65-71.
7 Smith EA, Malone RE. The outing of Philip Morris: advertising tobacco to gay men. Am J Public Health 2003;93:988-93.

8 Offen N, Smith EA, Malone RE. From adversary to target market: the ACT-UP boycott of Philip Morris. Tob Control 2003;12:203-7.

9 Yerger VB, Malone RE. African American leadership groups: smoking with the enemy. Tob Control 2002;11:336-45.

10 Offen N, Smith EA, Malone R. The perimetric boycott: a tool for tobacco control advocacy. Tob Control 2005;14:272-7.

11 Eliason MJ, Dibble SL, Gordon R, et al. The last drag: an evaluation of an LGBT-specific smoking intervention. J Homosex 2012:59:864-78.

12 Smith EA, Malone RE. Philip Morris's health information website appears responsible but undermines public health. Public Health Nursing 2008:25:570-80.

13 California LGBT Tobacco Education Partnership. A guide to tobacco-free pharmacies. San Francisco: Tobacco Education Clearinghouse of California, 2010

14 California LGBT Tobacco Education Partnership. Elected officials taking a stand against the tobacco industry. 2016. http://www.lgbtpartnership.org/ officials.htm

15 Last Drag. LGBT Organizations taking a stand agains the tobacco industry. 2016. http://www.lastdrag.org/ cleanmoney.html

16 Fallin A, Davis B. LGBT organisation successfully advocated for ban on tobacco promotions in San Jose, California. Tob Control 2016:25:504-5.

17 Fallin A, Goodin A, Lee YO, et al. Smoking characteristics among lesbian, gay, and bisexual adults. Prev Med 2015;74:123-30. 